Burgess Rosemary (Orcid ID: 0000-0002-2664-4395)

Scheffer Ingrid (Orcid ID: 0000-0002-2311-2174)

Berkovic Samuel (Orcid ID: 0000-0003-4580-841X)

\title{
SCN1A variants in vaccine-related febrile seizures: a prospective study
}

Damiano JA ${ }^{1^{*}}$; Deng L 2,3*; Li WH ${ }^{1,4}$; Burgess R ${ }^{1}$; Schneider AL ${ }^{1}$, Crawford NW 5, 6; Buttery J 6, 7; Gold M 8,; Richmond P 9, 10; Macartney KK 2, 3; Hildebrand MS 1,6; Scheffer IE 1, 5, 6, 11, Wood N 2, 3; Berkovic SF ${ }^{1}$.

1. Department of Medicine, University of Melbourne, Austin Hospital, Heidelberg, Australia

2. National Centre for Immunisation Research and Surveillance, The Children's Hospital at Westmead, Sydney, Australia

3. Children's Hospital Westmead Clinical School, The University of Sydney, Sydney, Australia;

4. Department of Neurology, Children's Hospital of Fudan University, Shanghai, China

5. Department of Paediatrics, University of Melbourne, Royal Children's Hospital, Parkville, Australia

6. Murdoch Children's Research Institute, Parkville, Australia

7. Infection and Immunity, Monash Children's Hospital, Department of Paediatrics Monash Centre for Health Care Research and Implementation, Monash University, Clayton, Australia

8. Discipline of Paediatrics, School of Medicine, Women's and Children's Hospital, University of Adelaide, Adelaide, Australia

9. Vaccine Trials Group, Wesfarmer's Centre of Vaccines and Infectious Disease, Telethon Kids Institute, and Dept of General Paediatrics, Perth Children's Hospital, Nedlands, Australia

10. Division of Paediatrics, School of Medicine, University of Western Australia, Perth, Australia

11. The Florey Institute of Neurosciences and Mental Health, Melbourne, Victoria, Australia *These authors contributed equally to this study

Key Words: Febrile seizures; fever; vaccination; SCN1A; Dravet syndrome; GEFS+

Manuscript word count: 2920

Abstract word count: 233

Number of tables: 5

Number of figures: 1

Number of references: 39

Running Head: SCN1A variants in vaccine-related febrile seizures

Corresponding author:

Prof. Samuel F. Berkovic

Epilepsy Research Centre, L2 Melbourne Brain Centre

245 Burgundy Street

Heidelberg, VIC 3084, Australia.

Tel: +6190357093

Fax: +61 94962291

This is the author manuscript accepted for publication and has undergone full peer review but has not been through the copyediting, typesetting, pagination and proofreading process, which may lead to differences between this version and the Version of Record. Please cite this article as doi: 10.1002/ana.25650

This article is protected by copyright. All rights reserved. 
Email: s.berkovic@unimelb.edu.au

This article is protected by copyright. All rights reserved. 


\begin{abstract}
Objective: Febrile seizures may follow vaccination. Common variants in the sodium channel gene, SCN1A, are associated with febrile seizures and rare pathogenic variants in SCN1A cause the severe developmental and epileptic encephalopathy Dravet Syndrome. Following vaccination, febrile seizures may raise the spectre of poor outcome and inappropriately implicate vaccination as the cause. We aimed to determine the prevalence of SCN1A variants in children having their first febrile seizure either proximal to vaccination, or unrelated to vaccination compared to controls.

Methods: We performed SCN1A sequencing, blind to clinical category, in a prospective cohort of children presenting with their first febrile seizure as vaccine proximate $(n=69)$, or as non-vaccine proximate $(n=75)$, and children with no history of seizures $(n=90)$ recruited in Australian paediatric hospitals.
\end{abstract}

Results: We detected two pathogenic variants in vaccine proximate cases (p.R568X and p.W932R), both of whom developed Dravet syndrome, and one in a non-vaccine proximate case (p.V947L) who had Febrile seizures plus from 9 months. All had generalised tonic-clonic seizures lasting longer than 15 minutes. We also found enrichment of a reported risk allele, rs6432860-T, in children with febrile seizures compared to controls (Odds Ratio 1.91 [95\% Cl 1.31- 2.81]).

Interpretation: Pathogenic SCN1A variants may be identified in infants with vaccine proximate febrile seizures. As early diagnosis of Dravet syndrome is essential for optimal management and outcome. SCN1A sequencing in infants with prolonged febrile seizures, proximate to vaccination, should become routine.

This article is protected by copyright. All rights reserved. 
Vaccination is a highly effective public health intervention that has led to a dramatic reduction in childhood morbidity and mortality from many infectious diseases. While vaccines have an excellent safety profile and usually only cause mild adverse reactions such as a fever, some individuals experience more serious adverse events, such as febrile seizures (FS).

FS following pertussis and measles-mumps-rubella (MMR) containing vaccines, as well as influenza vaccines in combination with pneumococcal vaccines, are well recognised, albeit uncommon (1-4). While epidemiological studies show that the vast majority of children with a history of FS develop normally $(5,6)$, a small proportion develop epilepsies (7), including the severe developmental and epileptic encephalopathy (DEE), Dravet syndrome $(8,9)$.

Pathogenic variants in the sodium channel alpha-1 subunit gene, SCN1A, cause Dravet syndrome in at least $80 \%$ of cases (8) and in $20 \%$ of cases of the milder syndrome of Genetic Epilepsy with Febrile Seizures plus (GEFS+) $(10,11)$. Vaccinations have been implicated in triggering earlier seizure onset in children with epilepsy with Dravet syndrome (12-15). We found that $30 \%(12 / 40)$ of a cohort of children with Dravet syndrome and SCN1A mutations had their first seizure within 2 days after vaccination (13). In terms of the frequency of $S C N 1 A$-associated Dravet syndrome amongst children with vaccination-related seizures, Verbeek et al. retrospectively identified 15/1269 (1.2\%) children with Dravet syndrome presenting with seizures following vaccination in the first 2 years of life (16). Thus, rare variants in SCN1A are associated with genetic epilepsies and DEEs that present with FS. Conversely, common variants have been implicated in the pathogenesis of FS alone, with a common SCN1A exonic variant (rs6432860) associated with increased risk of FS in general, but not with MMRrelated FS (17).

Aside from these retrospective studies, little is known about genetic variants in children with Vaccineproximate Febrile Seizures (VP-FS) and if FS differ from those triggered by another cause. It is also 
unknown whether the common rs6432860 variant, only identified in one population to date, is also a risk factor in non-Danish subjects with FS.

This study is the first to prospectively identify the presence and proportion of sodium channel variants among infants with VP-FS or Non-vaccine proximate Febrile Seizures (NVP-FS, compared with controls who have no history of seizures.

\section{Methods}

\section{Study design and participants}

This prospective study was conducted across four Australian tertiary paediatric hospitals that participate in the Paediatric Active Enhanced Disease Surveillance (PAEDS) network (18): The Children's Hospital at Westmead Sydney, Royal Children's Hospital Melbourne, Princess Margaret Hospital for Children Perth and Women's and Children's Hospital Adelaide. Participant recruitment occurred between 1 May 2013 and 20 April 2016.

From May 2013 to June 2014, children presenting with FS at these sites were identified through daily surveillance nurse screening of emergency presentations or hospital admissions coded with the ICD, Tenth Revision, Australian Modification (ICD-10-AM) diagnosis code for FS (code R56.0) as part of a larger cohort study (19). All VP-FS cases aged $<30$ months from this larger cohort study were invited to participate in this prospective study and equivalent numbers of NVP-FS cases of similar age was invited. Due to low numbers of VP-FS presentations during the initial recruitment period, additional VP-FS cases were recruited from July 2014 to April 2016 through outpatient attendance to Specialist Immunisation Clinics at any of the participating hospitals for review of a FS following vaccination or through VP-FS reports to the Serious Adverse Events following Vaccination in the Community service responsible for the recording and follow-up of all adverse events following immunisation in Victoria.

This article is protected by copyright. All rights reserved. 
Vaccine exposure was confirmed using immunisation records obtained from the Australian Immunisation Register, a national population-level register (20)

We defined a first FS case in this study as a child aged 30 months or less at the time of their first FS, the seizure fulfilled the Brighton Collaboration case definition as verified by clinician review of hospital records (21) and was associated with a temperature of $\geq 38^{\circ} \mathrm{C}$ measured by the parents or documented in the medical records in a child with no previous history of seizures. To capture all seizures associated with a fever following vaccination, including those following the 6-week and 4month vaccination time points, a lower age limit restriction was not used in this study. FS were categorised as VP-FS, defined as within 48 hours of an inactivated vaccine, or between 5-14 days of a live vaccine or within 14 days of a combination of inactivated and live vaccine. NVP-FS were defined as a FS outside of this period. Immunisation records obtained from the Australian Immunisation Register were used to confirm all vaccine exposures. (20)

Control participants were defined as children aged 12 to 42 months with no personal or family history of febrile or afebrile seizures. They were recruited through friends of children with FS already recruited into the study, children participating in other clinical trials at each recruitment site, and advertisements placed in local community newspapers, childcare centres and hospital notices. Children were excluded from the study if they had a pre-existing diagnosis of developmental delay, intellectual disability, medical or genetic condition that may affect cognition.

Thus, the phenotypic data allowed classification of participants into three groups: VP-FS, NVP-FS and aged matched controls without febrile seizures. This study was approved by the Sydney Children's Hospital Network Human Research Ethics Committee (HREC/14/SCHN/135).

\section{Clinical details and follow up}

This article is protected by copyright. All rights reserved. 
For FS cases, initial seizure details were collected from medical records and parent/carer interviews. Cases were contacted 12 to 24 months following the initial FS. Data on the occurrence, type (febrile or afebrile) and frequency of subsequent seizures following the initial FS and developmental progression were obtained from parent/carer interview and review of medical records, where available. Participants' development, executive function and behaviour were formally assessed using standardised assessment tools 12 to 24 months following their initial FS. Participants were assessed using Bayley Scales for Infant and Toddler Development, Third Edition, Woodcock-Johnson Tests of Achievement, Third Edition, Behavior Rating Inventory of Executive Function and Preschool Version and Child Behaviour Checklist - Preschool. Outcomes of these assessments will be reported separately. Additional history regarding subsequent developmental progression was obtained via medical records for cases with SCN1A variants.

\section{DNA extraction}

For gene variant screening, whole blood was obtained and genomic DNA extracted using QIAamp DNA Maxi Kits (Qiagen, Valencia, CA, USA). In some cases, saliva samples was obtained using Oragene kits and genomic DNA extracted using prepIT-L2P kits (DNA Genotek Inc., Ottawa, ON, Canada).

\section{PCR and Sanger Sequencing}

Coding regions of SCN1A (Chromosome 2: 165,984,641-166,149,214; NM_001165963;

ENST00000303395.8) including splice sites and up to 200 base pairs of intronic sequence were sequenced. Amplicons were PCR amplified using gene-specific primers designed to the reference human gene transcript (22). Primer sequences are available upon request. Amplification reactions were cycled using a standard protocol on a Veriti Thermal Cycler (Applied Biosystems, Carlsbad, CA). Bidirectional sequencing of all exons and flanking regions including splice sites was completed with a BigDye TM v3.1 Terminator Cycle Sequencing Kit (Applied Biosystems) according to the

This article is protected by copyright. All rights reserved. 
manufacturer's instructions. Sequencing products were resolved using a 3730xI DNA Analyzer (Applied Biosystems). All sequencing chromatograms were compared to published cDNA sequence and flanking intronic sequences. Nucleotide changes were detected using Codon Code Aligner (CodonCode Corporation, Dedham, MA). Molecular analysis was performed blind to the patients' clinical status.

\section{Variant Classification}

Each variant detected in SCN1A was classified into pathogenic, likely pathogenic, uncertain significance, likely benign and benign, according to according to American College of Medical Genetics (ACMG) consensus guidelines (23).

The following online genetic databases were used to help determine classification of variants: Database of Single Nucleotide Polymorphisms (dbSNP)(24), ClinVar(25), Genome Aggregation Database (gnomAD)(26), and Guangzhou Medical University Institute of Neuroscience SCN1A Mutation Database(27).

\section{Statistical analysis}

The three groups were compared using Pearson's chi-square or Fisher's exact test for categorical values and independent t-test for parametric continuous values. The primary outcome measure was the proportion of pathogenic and likely pathogenic SCN1A variants between groups compared using Fisher's Exact test. Pearson's chi-square or Fisher's Exact tests were also used to compare allele frequencies and genotype differences for synonymous and intronic variants between all three groups and between all FS and controls. The Bonferroni-Holm method was applied to control the error rate for multiple comparisons.

\section{Results}

This article is protected by copyright. All rights reserved. 


\section{Study cohort}

Of the 269 participants initially recruited, 35 were excluded: 26 for history of previous FS; 6 for no DNA sample collected or no consent given for genetic testing; 1 for lack of documented fever on case review; and 2 for withdrawal from the study. Of the remaining 234 subjects, 69 had VP-FS, 75 had NVP-FS, and 90 were controls. (Figure 1)

There were no differences in proportion of FS cases with a family history of FS or epilepsy between VP-FS and NVP-FS groups. Participants with VP-FS were younger at time of first FS than those with NVP-FS (12.8 months vs 14.3 months, $p=0.05)$ and more frequently had complex FS, defined by one of three criteria: lasting more than 15 minutes, focal features or more than one FS in 24 hours (39.1\% vs. $22.7 \%, p=0.03$ ) (Table 1). There was no difference in the proportion of patients' with recurrent FS or afebrile seizures over a similar follow-up period (VP-FS vs NVP-FS: $37.7 \%$ vs $34.7 \%, p=0.66$ for FS; $11.6 \%$ vs. 5.3\%, p=0.17 for afebrile seizures; follow-up 16.1 (SD 4.8) vs 17.2 (SD 3.2) months, $\mathrm{p}=0.09)$

\section{Variant Detection}

We detected 90 variants in SCN1A in the 234 subjects. The variants comprised of 1 nonsense (stop gain), 8 missense, 9 synonymous and 28 intronic variants; 44 variants were observed more than once. Table 2 shows the distribution of variants according to clinical group and ACMG guidelines (23).

There were three pathogenic or likely pathogenic variants found. Two were in the VP-FS group (2.9\%) and one in the NVP-FS group (1.3\%), with no difference between the three groups. Case 1 with VPFS had a recurrent nonsense mutation, p.R568X,,that was pathogenic in a patient with Dravet syndrome (28). Case 2 with VP-FS and 3 with NVP-FS had novel missense variants, p.W932R and p.V947L, respectively, both classified as "likely pathogenic" (variant details according to ACMG guidelines in footnotes to Table 3)

This article is protected by copyright. All rights reserved. 
Three missense changes were classified as 'unknown significance' p.A1161T (rs201079458); p.E1957G (rs121918802); p.T1250M (rs140731963)], which all were previously reported with a minor allele frequency (MAF) $<0.01$ in gnomAD, each had low predictions of functional effect from in silico tools or are reported as inherited (29); (30); (31). In our study, all three were found in the NVP-FS group and none of the cases had a family history of FS; segregation data was not available. A further three missense variants (p. R542Q (rs121918817), p. A1067T (rs2298771), p. T1174S (rs121918799), were classified as 'likely benign' or 'benign'.

The remaining variants of unknown significance comprised; three previously unreported intronic variants (c.4339-96delC; c.1-182delT; c.4339-110 delT) and a further nine rare intronic changes (rs571600918, rs749370340, rs73969742, rs549232924, rs75022359, rs76220226, rs8191989, rs773635222, rs148640356). We also identified six synonymous variants (rs140237315, rs141051370, rs374087499, rs144679294, rs569598595, rs145101180) with a minor allele frequency (MAF) $<0.01$ according to the Exome Aggregation Consortium (EXAC) database (26). The significance of these rare variants to FS is unknown.

\section{Common Variant Burden}

Three common coding variants c.3199G>A; p. A1067T (rs2298771), c.1212 A>G; p. V404V (rs7580482), c.2292; T>C;p. V764V (rs6432860) and two intronic variants, one c.603-91G>A (rs3812718) previously implicated as a risk allele for FS in a genome-wide study (17), and one in close proximity c.603-106 T>G (rs3812719), were investigated for differences in allele frequencies and genotype frequency between the groups (Table 4). The synonymous change, c.2292; C>T; p.V764V, rs6432860, was more frequently found in FS cases compared to controls (OR 1.91 [95\% Cl 1.31- 2.81]; $p=0.004)$. There was, however, no difference in frequency between the VP-FS and NVPFS groups (Table 5).

This article is protected by copyright. All rights reserved. 


\section{SCN1A pathogenic variant cases: phenotype and outcome}

The phenotypes of the three children with pathogenic or likely pathogenic SCN1A variants are described in Table 3. The two VP-FS cases had seizure onset within 24 hours of receiving their 4month vaccinations with Infanrix $\mathrm{Hexa}^{\circledR}$ (hexavalent vaccine with diphtheria, tetanus, acellular pertussis, hepatitis $B$, inactivated poliovirus and haemophilus influenza type B), Prevenar13 ${ }^{\circledR}$ (13valent pneumococcal conjugate vaccine) and Rotarix ${ }^{\circledR}$ (oral live-attenuated rotavirus vaccine). Both had prolonged generalised tonic-clonic seizures (GTCS), lasting 30 and 15 minutes respectively, and developed later seizure types that were not vaccine-proximate, including myoclonic, absence, hemiclonic, generalised clonic seizures and status epilepticus in the first two years of life. Case 1 with nonsense mutation, p.R568X, had developmental stagnation from 12 to 18 months with subsequent regression and developmental delay. Case 2 with the novel p.W932R mutation, had significant speech delay with no language or social-emotional developmental progression from age 18 months. The classical electro-clinical history led to a diagnosis of Dravet syndrome in both children. Both cases have subsequently received further vaccinations under close medical supervision, with regular anti-pyretic and benzodiazepine administration following vaccination in addition to their regular antiepileptic medication, without experiencing a seizure.

The NVP-FS case with a "likely pathogenic", novel variant, p.V947L, was a dizygous twin who had his first FS at 9 months; a 57 minute episode of tonic-clonic status epilepticus in the context of an upper respiratory tract infection. He proceeded to have frequent (up to 10 per year) tonic-clonic seizures, many but not all associated with fever. His co-twin did not have seizures, but their father had a history of frequent FS. His last known seizure was at age 5 years. Bayleys-III assessment at 18 months revealed mild fine motor delay and language delay. The diagnosis was febrile seizures plus (FS+), in the setting of a family with GEFS+ $(10,11)$.

\section{Discussion}


This is the first prospective study examining the frequency of SCN1A variants in children with FS triggered by vaccination compared those with FS unrelated to vaccination, and controls with no history of seizures. Of 144 patients with FS, only three (2\%) had pathogenic variants in SCN1A. There was no statistical difference in the frequency of pathogenic SCN1A variants between the groups from our cohort. It is of clinical relevance, however, that all three infants with pathogenic variants had prolonged FS and the two infants with vaccine-proximate FS both developed the features of Dravet syndrome. The third child with FS unrelated to vaccination had complex FS and afebrile seizures with a diagnosis of FS+. Our data suggest that a prolonged VP-FS in the first 6 months of life, lasting 15 minutes or more, in the presence of a pathogenic SCN1A variant, is suggestive of Dravet syndrome.

These findings are congruent with the retrospective analysis of a Dutch passive reporting database (16) which found that $1.2 \%(15 / 1269)$ of children with seizures, including febrile, afebrile and unclassified seizures, after vaccination in the first 2 years of life had SCN1A-related Dravet syndrome. Our two Dravet syndrome patients presented with prolonged seizures at 4 months occurring within 24 hours of vaccination, similar to the Dutch cases. The younger age at presentation of these children, compared to the median onset of FS at age 18 months, mirrors our finding of vaccine-proximate onset in Dravet syndrome being associated with seizure onset at 4 months rather than the mean onset of Dravet syndrome of 6 months $(8,13)$. The reported vaccine-related first seizures in Verbeek's study involved whole-cell pertussis vaccines, whereas the SCN1A-related Dravet cases in our cohort had their first FS following acellular vaccines, suggesting that the genetic immunological interaction may be independent of the type of pertussis vaccine involved. While a follow up study by Verbeek et al.(32) showed a reduction in risk of subsequent vaccine related seizures with acellular pertussis vaccines, as with the general paediatric population (33), the type of vaccine does not appear to affect the initial vaccine related seizure presentation in children with Dravet syndrome. 
In addition to the pathogenic and likely pathogenic variants identified, we confirmed a higher frequency of the common SCN1A variant allele, c.2292; C>T; p.V764V in FS cases compared to controls. This FS risk allele was first identified in a Danish genome-wide association study (17) and we are the first to confirm the association of this allele to FS outside of a Danish population. As our study only examined SCN1A variants, we could not verify the other loci reported to be associated with MMR-related FS and FS.

This study has some limitations. With the yield of pathogenic variants that we found, our sample size was not powered to detect a significant difference between the groups using Fisher's Exact test in the frequency of SCN1A variants. The SCN1A mutation rate may also be underestimated as Sanger sequencing cannot reliably detect intragenic deletions (34) and mosaicism rates below $20 \%$ that have been previously found in SCN1A-associated FS(35). Other genes associated with FS including other sodium channel genes (SCN1B, SCN8A, and SCN2A), the y2-subunit of gamma-aminobutyric acid (GABA) receptor subunit (GABRG2) (36), and Protocadherin 19 (PCDH19) were not examined.

Our prospective study suggests that in an infant with vaccine proximate, prolonged FS, the detection of a pathogenic SCN1A variant should raise the suspicion of Dravet syndrome. Given that a higher rate of seizures with subsequent vaccinations occurs in Dravet syndrome (32), screening for SCN1A variants in children 12 months and under with prolonged VP-FS, should be considered for early diagnosis and optimal management. Early initiation and appropriate choice of anti-epileptic medication for children with Dravet syndrome can lead to better long-term outcomes $(37,38)$. As children receive multiple vaccines in the first 18 months of life, early identification of this at-risk group can also assist in the planning of safe administration of subsequent vaccinations in these children to reduce the risk of vaccine-preventable diseases and associated complications.

This article is protected by copyright. All rights reserved. 


\section{Acknowledgements}

We thank the patients and families for their participation in this study. We thank all the research assistants and nurses involved in the coordination and data collection for this study: the late Karen Orr, Rosemary Joyce, Alissa McMinn, Annette Alafaci, Mary Walker, Emily Watson, Daniela Calderisi, Rachel West, Jane Jones and Heidi Hutton. We thank Rebekah Stubbs and Timothy Green (Epilepsy Research Centre, University of Melbourne) for performing the genomic DNA extractions.

This study is supported by National Health and Medical Research Council (NHMRC) (Project Grant ID 1049557); NHMRC Program Grant (1091593) to S.F.B and I.E.S, a Practitioner Fellowship (1006110) to I.E.S, a Project Grant (1129054) to S.F.B, NHMRC Career Development Fellowship (1063629) to N.W, University of Sydney Research Training Program scholarship to L.D. and a Project Grant (1079058) and a R.D Wright Career Development Fellowship (1063799) to M.S.H.

\section{Author contribution}

NW, SFB and IES contributed to the conception and design of the study. JAD, LD, LWH, RB, ALS, NWC, JB, MG, PR, KKM and MSH contributed to the acquisition and analysis of data. J.A.D. and L.D. drafted the text, figure and tables with support from SFB, NW and IES.

\section{Potential conflict of interest}

S.F.B and I.E.S's institution (University of Melbourne) receives payments for a patent for SCN1A testing held by Bionomics Inc and licensed to various diagnostic companies. The remaining authors have no conflicts of interest.

This article is protected by copyright. All rights reserved. 


\section{References}

1. Barlow WE, Davis RL, Glasser JW, Rhodes PH, Thompson RS, Mullooly JP, et al. The risk of seizures after receipt of whole-cell pertussis or measles, mumps, and rubella vaccine. The New England journal of medicine. 2001;345(9):656-61.

2. Gold MS, Effler P, Kelly H, Richmond PC, Buttery JP. Febrile convulsions after 2010 seasonal trivalent influenza vaccine: implications for vaccine safety surveillance in Australia. The Medical journal of Australia. 2010;193(9):492-3.

3. Tse A, Tseng HF, Greene SK, Vellozzi C, Lee GM. Signal identification and evaluation for risk of febrile seizures in children following trivalent inactivated influenza vaccine in the Vaccine Safety Datalink Project, 2010-2011. Vaccine. 2012;30(11):2024-31.

4. Macartney KK, Gidding HF, Trinh L, Wang H, McRae J, Crawford N, et al. Febrile seizures following measles and varicella vaccines in young children in Australia. Vaccine. 2015;33(11):1412-7.

5. Verity CM, Greenwood R, Golding J. Long-term intellectual and behavioral outcomes of children with febrile convulsions. The New England journal of medicine. 1998;338(24):1723-8.

6. Chang YC, Guo NW, Huang CC, Wang ST, Tsai JJ. Neurocognitive attention and behavior outcome of school-age children with a history of febrile convulsions: a population study. Epilepsia. 2000;41(4):412-20.

7. Annegers JF, Hauser WA, Shirts SB, Kurland LT. Factors prognostic of unprovoked seizures after febrile convulsions. The New England journal of medicine. 1987:493.

8. Marini C, Mei D, Temudo T, Ferrari AR, Buti D, Dravet C, et al. Idiopathic epilepsies with seizures precipitated by fever and SCN1A abnormalities. Epilepsia. 2007;48(9):1678-85.

9. von Spiczak S, Helbig I, Drechsel-Baeuerle U, Muhle H, van Baalen A, van Kempen MJ, et al. A retrospective population-based study on seizures related to childhood vaccination. Epilepsia. 2011;52(8):1506-12.

10. Zhang YH, Burgess R, Malone JP, Glubb GC, Helbig KL, Vadlamudi L, et al. Genetic epilepsy with febrile seizures plus: Refining the spectrum. Neurology. 2017;89(12):1210-9.

11. Myers KA, Scheffer IE, Berkovic SF, Commission IG. Genetic literacy series: genetic epilepsy with febrile seizures plus. Epileptic disorders : international epilepsy journal with videotape. 2018;20(4):232-8.

12. Berkovic SF, Harkin L, McMahon JM, Pelekanos JT, Zuberi SM, Wirrell EC, et al. Denovo mutations of the sodium channel gene SCN1A in alleged vaccine encephalopathy: a retrospective study. Lancet Neurol. 2006;5(6):488-92.

13. McIntosh AM, McMahon J, Dibbens LM, Iona X, Mulley JC, Scheffer IE, et al. Effects of vaccination on onset and outcome of Dravet syndrome: a retrospective study. Lancet Neurol. 2010;9(6):592-8.

14. Zamponi N, Passamonti C, Petrelli C, Veggiotti P, Baldassari C, Verrotti A, et al. Vaccination and occurrence of seizures in SCN1A mutation-positive patients: a multicenter Italian study. Pediatric neurology. 2014;50(3):228-32.

15. Wong PT, Wong VC. Prevalence and Characteristics of Vaccination Triggered Seizures in Dravet Syndrome in Hong Kong: A Retrospective Study. Pediatric neurology. 2016;58:41-7. 
16. Verbeek NE, van der Maas NA, Jansen FE, van Kempen MJ, Lindhout D, Brilstra EH. Prevalence of SCN1A-related dravet syndrome among children reported with seizures following vaccination: a population-based ten-year cohort study. PloS one. 2013;8(6):e65758. 17. Feenstra B, Pasternak B, Geller F, Carstensen L, Wang T, Huang F, et al. Common variants associated with general and MMR vaccine-related febrile seizures. Nature genetics. 2014;46(12):1274-82.

18. Zurynski Y, McIntyre P, Booy R, Elliott EJ, Group PI. Paediatric active enhanced disease surveillance: a new surveillance system for Australia. J Paediatr Child Health. 2013;49(7):588-94.

19. Deng L, Gidding H, Macartney K, Crawford N, Buttery J, Gold M, et al. Postvaccination Febrile Seizure Severity and Outcome. Pediatrics. 2019;143(5).

20. Hull BP, Hendry AJ, Dey A, Beard FH, Brotherton JM, McIntyre PB. Immunisation coverage annual report, 2014. Communicable diseases intelligence quarterly report. 2017;41(1):E68-E90.

21. Bonhoeffer J, Menkes J, Gold MS, de Souza-Brito G, Fisher MC, Halsey N, et al. Generalized convulsive seizure as an adverse event following immunization: case definition and guidelines for data collection, analysis, and presentation. Vaccine. 2004;22(5-6):557-62.

22. Gene. Bethesda (MD): National Center for Biotechnology Information, National Library of Medicine. ; 2018 [Available from: https://www.ncbi.nlm.nih.gov/gene.

23. Richards S, Aziz N, Bale S, Bick D, Das S, Gastier-Foster J, et al. Standards and guidelines for the interpretation of sequence variants: a joint consensus recommendation of the American College of Medical Genetics and Genomics and the Association for Molecular Pathology. Genetics in medicine : official journal of the American College of Medical Genetics. 2015;17(5):405-24.

24. Database of Single Nucleotide Polymorphisms (dbSNP). Bethesda (MD): National Center for Biotechnology Information, National Library of Medicine. ; 2018 [Available from: http://www.ncbi.nlm.nih.gov/SNP/.

25. Landrum MJ, Lee JM, Benson M, Brown GR, Chao C, Chitipiralla S, et al. ClinVar: improving access to variant interpretations and supporting evidence. Nucleic acids research. 2018;46(D1):D1062-d7.

26. Lek M, Karczewski KJ, Minikel EV, Samocha KE, Banks E, Fennell T, et al. Analysis of protein-coding genetic variation in 60,706 humans. Nature. 2016;536(7616):285-91.

27. SCN1A Mutation Database. Guangzhou, China.: Institute of Neuroscience and The Second Affiliated Hospital of Guangzhou Medical University, Key Laboratory of Neurogenetics and Channelopathies of Guangdong Province and the Ministry of Education of China, Collaborative Innovation Center for Neurogenetics and Channelopathies.; 2014 [Available from: http://www.caae.org.cn/gzneurosci/scn1adatabase/index.php.

28. Ohmori I, Ohtsuka Y, Ouchida M, Ogino T, Maniwa S, Shimizu K, et al. Is phenotype difference in severe myoclonic epilepsy in infancy related to SCN1A mutations? Brain \& development. 2003;25(7):488-93.

29. Orrico A, Galli L, Grosso S, Buoni S, Pianigiani R, Balestri P, et al. Mutational analysis of the SCN1A, SCN1B and GABRG2 genes in 150 Italian patients with idiopathic childhood epilepsies. Clinical genetics. 2009;75(6):579-81. 
30. Escayg A, Heils A, MacDonald BT, Haug K, Sander T, Meisler MH. A novel SCN1A mutation associated with generalized epilepsy with febrile seizures plus--and prevalence of variants in patients with epilepsy. American journal of human genetics. 2001;68(4):866-73.

31. Wallace RH, Hodgson BL, Grinton BE, Gardiner RM, Robinson R, Rodriguez-Casero $\mathrm{V}$, et al. Sodium channel alpha1-subunit mutations in severe myoclonic epilepsy of infancy and infantile spasms. Neurology. 2003;61(6):765-9.

32. Verbeek NE, van der Maas NA, Sonsma AC, Ippel E, Vermeer-de Bondt PE, Hagebeuk $\mathrm{E}$, et al. Effect of vaccinations on seizure risk and disease course in Dravet syndrome. Neurology. 2015;85(7):596-603.

33. Le Saux N, Barrowman NJ, Moore DL, Whiting S, Scheifele D, Halperin S, et al. Decrease in hospital admissions for febrile seizures and reports of hypotonic-hyporesponsive episodes presenting to hospital emergency departments since switching to acellular pertussis vaccine in Canada: a report from IMPACT. Pediatrics. 2003;112(5):e348.

34. Marini C, Scheffer IE, Nabbout R, Mei D, Cox K, Dibbens LM, et al. SCN1A duplications and deletions detected in Dravet syndrome: implications for molecular diagnosis. Epilepsia. 2009;50(7):1670-8.

35. Myers CT, Hollingsworth G, Muir AM, Schneider AL, Thuesmunn Z, Knupp A, et al. Parental Mosaicism in "De Novo" Epileptic Encephalopathies. New England Journal of Medicine

2018. p. 1646-8.

36. Audenaert D, Van Broeckhoven C, De Jonghe P. Genes and Loci Involved in Febrile Seizures and Related Epilepsy Syndromes. Human mutation. 2006(5):391.

37. Wirrell EC, Laux L, Donner E, Jette N, Knupp K, Meskis MA, et al. Original Article: Optimizing the Diagnosis and Management of Dravet Syndrome: Recommendations From a North American Consensus Panel. Pediatric neurology. 2017;68:18-34.e3.

38. Cetica V, Chiari S, Mei D, Parrini E, Grisotto L, Marini C, et al. Clinical and genetic factors predicting Dravet syndrome in infants with SCN1A mutations. Neurology. 2017(11):1037.

39. Zuberi SM, Brunklaus A, Birch R, Reavey E, Duncan J, Forbes GH. Genotypephenotype associations in SCN1A-related epilepsies. Neurology. 2011;76(7):594-600. 
Figure legend

Figure 1: Study cohort

This article is protected by copyright. All rights reserved. 


\section{Table Legends}

Table 1: Clinical details for Vaccine Proximate-FS (VP-FS), Non-Vaccine Proximate-FS (NVP-FS) and control groups

$\mathrm{FS}=$ febrile seizure, $\mathrm{AFS}=$ afebrile seizure, $\mathrm{SD}=$ standard deviation, $\mathrm{NA}=$ not applicable Complex FS $=$ febrile seizure $>15$ minutes, focal seizure or repeat seizure within $24 \mathrm{~h}$ of initial

*Where there is no value for control group, $p$ value compares VP-FS and NVP-FS groups only

Table 2: SCN1A variants by group allocation and variant class

VP-FS=vaccine proximate febrile seizure, NVP-FS=non-vaccine proximate febrile seizure $\mathrm{ACMG}=$ American College of Medical Genetics

* Variants of unknown significance were all intronic in VP-FS and control groups; NVP-FS group had three missense, 1 synonymous and four intronic variants

Table 3: Clinical characteristics of participants with pathogenic/likely pathogenic variants

FS=febrile seizure, VP-FS=vaccine proximate FS, NVP-FS=non-vaccine proximate FS, FS+ = febrile seizures plus, DTPa-IPV-HepB-HiB=hexavalent diphtheria, tetanus, acellular pertussis, inactivated polio, hepatitis $B$, haemophilus influenza $B$ vaccine, PCV13 $=13$ valent pneumococcal conjugate vaccine, GTCS=generalised tonic-clonic seizures;

GCS=generalised clonic seizures; $M=$ =myoclonic seizures; $A b=a b s e n c e s ; ~ S E=s t a t u s$ epilepticus; $\mathrm{H}=$ hemiclonic; $\mathrm{NA}=$ not applicable.

† Classification according to ACMG guidelines (23) is listed and qualifying criteria specified

\# Null variant, previously reported $(8,29)$

* Novel missense change at an amino acid residue where a different missense change determined to be pathogenic has been seen before (39); located in a mutational hot spot; absent from controls

^Located in a mutational hot spot; absent from controls; Multiple lines of computational evidence support a deleterious effect on the gene, Missense variant in a gene that has a low rate of benign missense variation and in which missense variants are a common mechanism of disease

Table 4: Allele frequency differences for the 5 common single nucleotide polymorphisms (SNPS) detected within SCN1A

a Includes both VP-FS and NVP-FS cases

${ }^{*} p$ value corrected for multiple comparisons using Bonferroni method using 5 tests

Table 5: Allele frequency comparisons for single nucleotide polymorphism (SNP) c.2292; C>T; p.V764V; rs6432860 according to clinical groups assignment 
FS=febrile seizure, VP-FS=vaccine proximate FS, NVP-FS=non-vaccine proximate FS ${ }^{*} p$ value corrected for multiple comparisons using Bonferroni method using 4 tests

This article is protected by copyright. All rights reserved. 


\section{Please wait...}

If this message is not eventually replaced by the proper contents of the document, your PDF viewer may not be able to display this type of document.

You can upgrade to the latest version of Adobe Reader for Windows®, Mac, or Linux® by visiting http://www.adobe.com/go/reader_download.

For more assistance with Adobe Reader visit http://www.adobe.com/go/acrreader.

Windows is either a registered trademark or a trademark of Microsoft Corporation in the United States and/or other countries. Mac is a trademark
of Apple Inc., registered in the United States and other countries. Linux is the registered trademark of Linus Torvalds in the U.S. and other countries. 


\section{Please wait...}

If this message is not eventually replaced by the proper contents of the document, your PDF viewer may not be able to display this type of document.

You can upgrade to the latest version of Adobe Reader for Windows®, Mac, or Linux® by visiting http://www.adobe.com/go/reader_download.

For more assistance with Adobe Reader visit http://www.adobe.com/go/acrreader.

Windows is either a registered trademark or a trademark of Microsoft Corporation in the United States and/or other countries. Mac is a trademark
of Apple Inc., registered in the United States and other countries. Linux is the registered trademark of Linus Torvalds in the U.S. and other countries. 


\section{Please wait...}

If this message is not eventually replaced by the proper contents of the document, your PDF viewer may not be able to display this type of document.

You can upgrade to the latest version of Adobe Reader for Windows®, Mac, or Linux® by visiting http://www.adobe.com/go/reader_download.

For more assistance with Adobe Reader visit http://www.adobe.com/go/acrreader.

Windows is either a registered trademark or a trademark of Microsoft Corporation in the United States and/or other countries. Mac is a trademark
of Apple Inc., registered in the United States and other countries. Linux is the registered trademark of Linus Torvalds in the U.S. and other countries. 


\section{ICMJE Form for Disclosure of Potential Conflicts of Interest}

\section{hitinitions}

The purpose of this form is to provide readers of your manuscript with information about your other interests that could influence how they receive and understand your work. The form is designed to be completed electronically and stored electronically. It contains programming that allows appropriate data display. Each author should submit a separate form and is responsible for the accuracy and completeness of the submitted information. The form is in six parts.

\section{Identifying information.}

\section{The work under consideration for publication.}

This section asks for information about the work that you have submitted for publication. The time frame for this reporting is that of the work itself, from the initial conception and planning to the present. The requested information is about resources that you received, either directly or indirectly (via your institution), to enable you to complete the work. Checking "No" means that you did the work without receiving any financial support from any third party -- that is, the work was supported by funds from the same institution that pays your salary and that institution did not receive third-party funds with which to pay you. If you or your institution received funds from a third party to support the work, such as a government granting agency, charitable foundation or commercial sponsor, check "Yes".

\section{Relevant financial activities outside the submitted work.}

This section asks about your financial relationships with entities in the bio-medical arena that could be perceived to influence, or that give the appearance of potentially influencing, what you wrote in the submitted work. You should disclose interactions with ANY entity that could be considered broadly relevant to the work. For example, if your article is about testing an epidermal growth factor receptor (EGFR) antagonist in lung cancer, you should report all associations with entities pursuing diagnostic or therapeutic strategies in cancer in general, not just in the area of EGFR or lung cancer.

Report all sources of revenue paid (or promised to be paid) directly to you or your institution on your behalf over the 36 months prior to submission of the work. This should include all monies from sources with relevance to the submitted work, not just monies from the entity that sponsored the research. Please note that your interactions with the work's sponsor that are outside the submitted work should also be listed here. If there is any question, it is usually better to disclose a relationship than not to do so.

For grants you have received for work outside the submitted work, you should disclose support ONLY from entities that could be perceived to be affected financially by the published work, such as drug companies, or foundations supported by entities that could be perceived to have a financial stake in the outcome. Public funding sources, such as government agencies, charitable foundations or academic institutions, need not be disclosed. For example, if a government agency sponsored a study in which you have been involved and drugs were provided by a pharmaceutical company, you need only list the pharmaceutical company.

\section{Intellectual Property.}

This section asks about patents and copyrights, whether pending, issued, licensed and/or receiving royalties.

\section{Relationships not covered above.}

Use this section to report other relationships or activities that readers could perceive to have influenced, or that give the appearance of potentially influencing, what you wrote in the submitted work.

\section{Definitions.}

Entity: government agency, foundation, commercial sponsor, academic institution, etc.

Grant: A grant from an entity, generally [but not always] paid to your organization

Personal Fees: Monies paid to you for services rendered, generally honoraria, royalties, or fees for consulting , lectures, speakers bureaus, expert testimony, employment, or other affiliations

Non-Financial Support: Examples include drugs/equipment supplied by the entity, travel paid by the entity, writing assistance, administrative support, etc.
Other: Anything not covered under the previous three boxes Pending: The patent has been filed but not issued Issued: The patent has been issued by the agency Licensed: The patent has been licensed to an entity, whether earning royalties or not

Royalties: Funds are coming in to you or your institution due to your patent 


\section{ICMJE Form for Disclosure of Potential Conflicts of Interest}

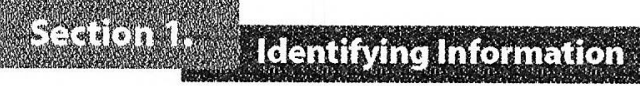

1. Given Name (First Name)

Nigel

4. Are you the corresponding author?

5. Manuscript Title

SCN1A variants in vaccine-related febrile seizures: a prospective study
2. Surname (Last Name)

Crawford
3. Date

15-October-2019

6. Manuscript Identifying Number (if you know it)

ANA-19-1109

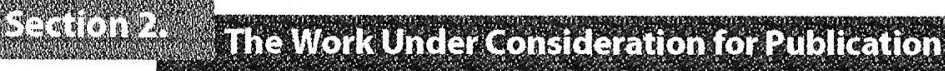

Did you or your institution at any time receive payment or services from a third party (government, commercial, private foundation, etc.) for any aspect of the submitted work (including but not limited to grants, data monitoring board, study design, manuscript preparation, statistical analysis, etc.)?

Are there any relevant conflicts of interest? $\square$ Yes $\square$ No

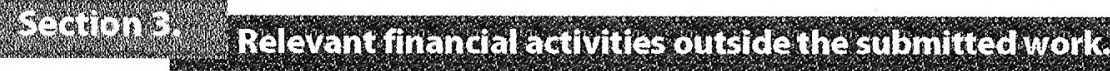

Place a check in the appropriate boxes in the table to indicate whether you have financial relationships (regardless of amount of compensation) with entities as described in the instructions. Use one line for each entity; add as many lines as you need by clicking the "Add +" box. You should report relationships that were present during the $\mathbf{3 6}$ months prior to publication. Are there any relevant conflicts of interest? $\square$ Yes $\square$ No

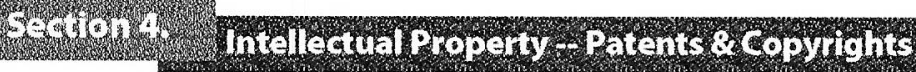

Do you have any patents, whether planned, pending or issued, broadly relevant to the work? $\square$ Yes $\square$ No 


\section{ICMJE Form for Disclosure of Potential Conflicts of Interest}

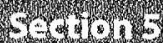

\section{Pedionships not covered bove}

Are there other relationships or activities that readers could perceive to have influenced, or that give the appearance of potentially influencing, what you wrote in the submitted work?

Yes, the following relationships/conditions/circumstances are present (explain below):

$\checkmark$ No other relationships/conditions/circumstances that present a potential conflict of interest

At the time of manuscript acceptance, journals will ask authors to confirm and, if necessary, update their disclosure statements. On occasion, journals may ask authors to disclose further information about reported relationships.

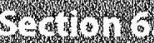

\section{Discrosing statenent}

Based on the above disclosures, this form will automatically generate a disclosure statement, which will appear in the box below.

Dr. Crawford has nothing to disclose.

trom

Please visit http://www.icmje.org/cgi-bin/feedback to provide feedback on your experience with completing this form. 


\section{ICMJE Form for Disclosure of Potential Conflicts of Interest}

\section{Instructions}

The purpose of this form is to provide readers of your manuscript with information about your other interests that could influence how they receive and understand your work. The form is designed to be completed electronically and stored electronically. It contains programming that allows appropriate data display. Each author should submit a separate form and is responsible for the accuracy and completeness of the submitted information. The form is in six parts.

\section{Identifying information.}

\section{The work under consideration for publication.}

This section asks for information about the work that you have submitted for publication. The time frame for this reporting is that of the work itself, from the initial conception and planning to the present. The requested information is about resources that you received, either directly or indirectly (via your institution), to enable you to complete the work. Checking "No" means that you did the work without receiving any financial support from any third party -- that is, the work was supported by funds from the same institution that pays your salary and that institution did not receive third-party funds with which to pay you. If you or your institution received funds from a third party to support the work, such as a government granting agency, charitable foundation or commercial sponsor, check "Yes".

\section{Relevant financial activities outside the submitted work.}

This section asks about your financial relationships with entities in the bio-medical arena that could be perceived to influence, or that give the appearance of potentially influencing, what you wrote in the submitted work. You should disclose interactions with ANY entity that could be considered broadly relevant to the work. For example, if your article is about testing an epidermal growth factor receptor (EGFR) antagonist in lung cancer, you should report all associations with entities pursuing diagnostic or therapeutic strategies in cancer in general, not just in the area of EGFR or lung cancer.

Report all sources of revenue paid (or promised to be paid) directly to you or your institution on your behalf over the 36 months prior to submission of the work. This should include all monies from sources with relevance to the submitted work, not just monies from the entity that sponsored the research. Please note that your interactions with the work's sponsor that are outside the submitted work should also be listed here. If there is any question, it is usually better to disclose a relationship than not to do so.

For grants you have received for work outside the submitted work, you should disclose support ONLY from entities that could be perceived to be affected financially by the published work, such as drug companies, or foundations supported by entities that could be perceived to have a financial stake in the outcome. Public funding sources, such as government agencies, charitable foundations or academic institutions, need not be disclosed. For example, if a government agency sponsored a study in which you have been involved and drugs were provided by a pharmaceutical company, you need only list the pharmaceutical company.

\section{Intellectual Property.}

This section asks about patents and copyrights, whether pending, issued, licensed and/or receiving royalties.

\section{Relationships not covered above.}

Use this section to report other relationships or activities that readers could perceive to have influenced, or that give the appearance of potentially influencing, what you wrote in the submitted work.

\section{Definitions.}

Entity: government agency, foundation, commercial sponsor, academic institution, etc.

Grant: A grant from an entity, generally [but not always] paid to your organization

Personal Fees: Monies paid to you for services rendered, generally honoraria, royalties, or fees for consulting , lectures, speakers bureaus, expert testimony, employment, or other affiliations

Non-Financial Support: Examples include drugs/equipment supplied by the entity, travel paid by the entity, writing assistance, administrative support, etc.
Other: Anything not covered under the previous three boxes Pending: The patent has been filed but not issued Issued: The patent has been issued by the agency Licensed: The patent has been licensed to an entity, whether earning royalties or not Royalties: Funds are coming in to you or your institution due to your patent 


\section{ICMJE Form for Disclosure of Potential Conflicts of Interest}

\section{Section 1. Identifying Information}

1. Given Name (First Name)

Lucy

4. Are you the corresponding author?
2. Surname (Last Name)

Deng

$\square$ Yes $\checkmark$ No $\quad$ Corresponding Author's Name

Samuel F Berkovic

5. Manuscript Title

SCN1A variants in vaccine-related febrile seizures: a prospective study

6. Manuscript Identifying Number (if you know it)

ANA-19-1109

\section{Section 2. The Work Under Consideration for Publication}

Did you or your institution at any time receive payment or services from a third party (government, commercial, private foundation, etc.) for any aspect of the submitted work (including but not limited to grants, data monitoring board, study design, manuscript preparation, statistical analysis, etc.)?

Are there any relevant conflicts of interest? $\square$ Yes $\square$ No

If yes, please fill out the appropriate information below. If you have more than one entity press the "ADD" button to add a row. Excess rows can be removed by pressing the " $\mathrm{X}$ " button.

\begin{tabular}{|l|c|c|c|c|l|}
\hline Name of Institution/Company & Grant? & $\begin{array}{c}\text { Personal } \\
\text { Fees? }\end{array}$ & $\begin{array}{c}\text { Non-Financial } \\
\text { Support? }\end{array}$ & Other? & Comments \\
\hline University of Sydney & $\square$ & $\square$ & $\square$ & $\square$ \\
\hline
\end{tabular}

\section{Section 3. Relevant financial activities outside the submitted work.}

Place a check in the appropriate boxes in the table to indicate whether you have financial relationships (regardless of amount of compensation) with entities as described in the instructions. Use one line for each entity; add as many lines as you need by clicking the "Add +" box. You should report relationships that were present during the $\mathbf{3 6}$ months prior to publication.

Are there any relevant conflicts of interest? $\square$ Yes $\square$ No

\section{Section 4. Intellectual Property -- Patents \& Copyrights}

Do you have any patents, whether planned, pending or issued, broadly relevant to the work? $\square$ Yes $\square$ No 


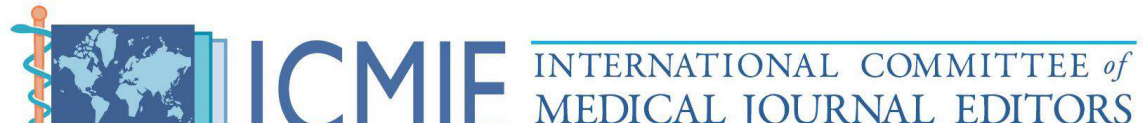 \\ MEDICAL JOURNAL EDITORS}

\section{ICMJE Form for Disclosure of Potential Conflicts of Interest}

\section{Section 5. Relationships not covered above}

Are there other relationships or activities that readers could perceive to have influenced, or that give the appearance of potentially influencing, what you wrote in the submitted work?

$\square$ Yes, the following relationships/conditions/circumstances are present (explain below):

$\checkmark$ No other relationships/conditions/circumstances that present a potential conflict of interest

At the time of manuscript acceptance, journals will ask authors to confirm and, if necessary, update their disclosure statements. On occasion, journals may ask authors to disclose further information about reported relationships.

\section{Section 6. Disclosure Statement}

Based on the above disclosures, this form will automatically generate a disclosure statement, which will appear in the box below.

Dr. Deng reports grants from University of Sydney, during the conduct of the study.

\section{Evaluation and Feedback}

Please visit http://www.icmje.org/cgi-bin/feedback to provide feedback on your experience with completing this form. 
Vaccine-proximate febrile seizures

69

\section{Total recruited}

269

Excluded:

1 no documented fever

2 withdrawn

6 no consent/DNA sample

26 previous FS (including 1 with genetic condition - tuberous sclerosis)

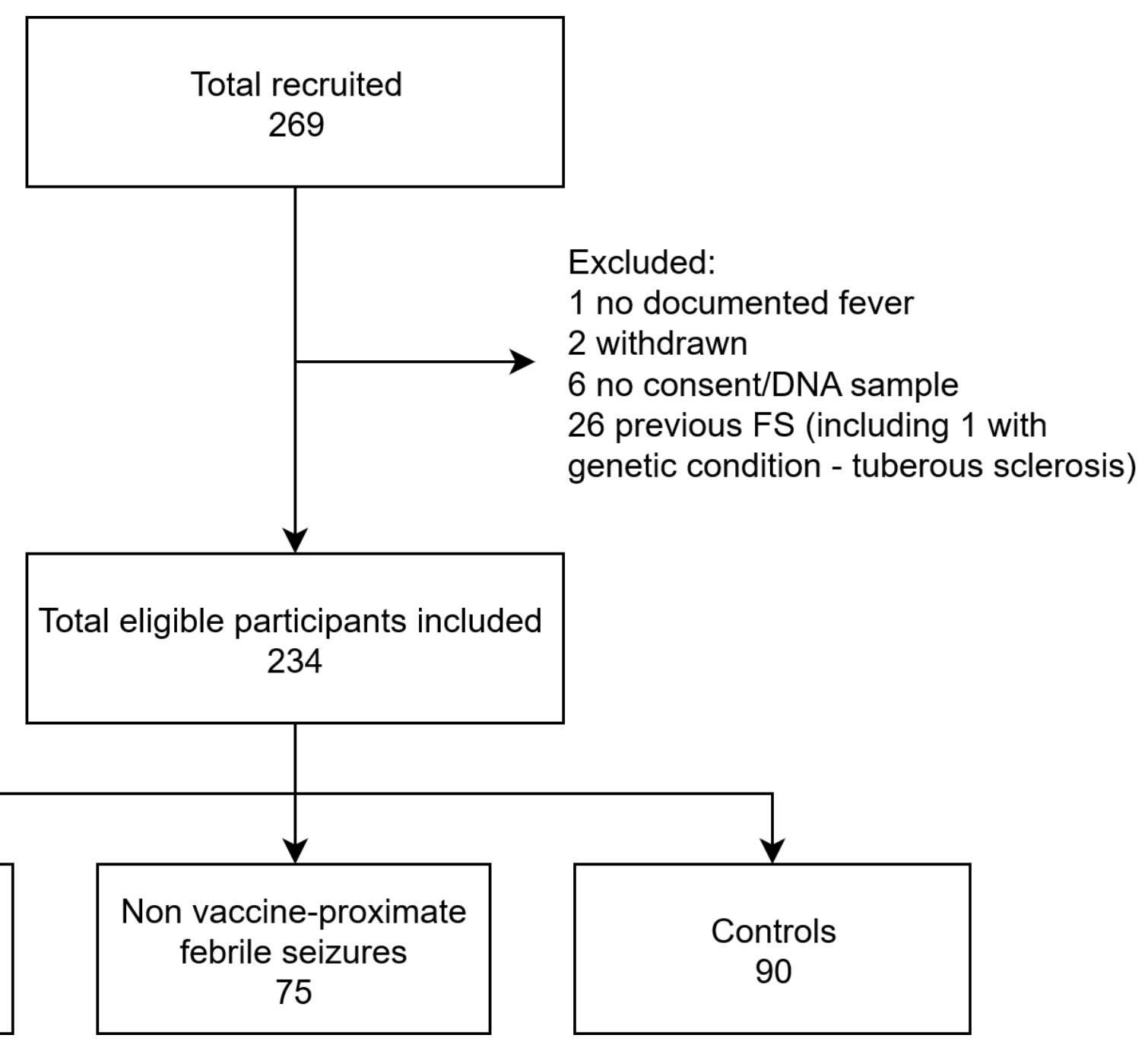

ANA_25650_Figure 1.tiff 


\section{ICMJE Form for Disclosure of Potential Conflicts of Interest}

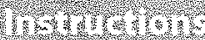

The purpose of this form is to provide readers of your manuscript with information about your other interests that could influence how they receive and understand your work. The form is designed to be completed electronically and stored electronically. It contains programming that allows appropriate data display. Each author should submit a separate form and is responsible for the accuracy and completeness of the submitted information. The form is in six parts.

\section{Identifying information.}

\section{The work under consideration for publication.}

This section asks for information about the work that you have submitted for publication. The time frame for this reporting is that of the work itself, from the initial conception and planning to the present. The requested information is about resources that you received, either directly or indirectly (via your institution), to enable you to complete the work. Checking "No" means that you did the work without receiving any financial support from any third party - that is, the work was supported by funds from the same institution that pays your salary and that institution did not receive third-party funds with which to pay you. If you or your institution received funds from a third party to support the work, such as a government granting agency, charitable foundation or commercial sponsor, check "Yes".

\section{Relevant financial activities outside the submitted work.}

This section asks about your financial relationships with entities in the bio-medical arena that could be perceived to influence, or that give the appearance of potentially influencing, what you wrote in the submitted work. You should disclose interactions with ANY entity that could be considered broadly relevant to the work. For example, if your article is about testing an epidermal growth factor receptor (EGFR) antagonist in lung cancer, you should report all associations with entities pursuing diagnostic or therapeutic strategies in cancer in general, not just in the area of EGFR or lung cancer.

Report all sources of revenue paid (or promised to be paid) directly to you or your institution on your behalf over the 36 months prior to submission of the work. This should include all monies from sources with relevance to the submitted work, not just monies from the entity that sponsored the research. Please note that your interactions with the work's sponsor that are outside the submitted work should also be listed here. If there is any question, it is usually better to disclose a relationship than not to do so.

For grants you have received for work outside the submitted work, you should disclose support ONLY from entities that could be perceived to be affected financially by the published work, such as drug companies, or foundations supported by entities that could be perceived to have a financial stake in the outcome. Public funding sources, such as government agencies, charitable foundations or academic institutions, need not be disclosed. For example, if a government agency sponsored a study in which you have been involved and drugs were provided by a pharmaceutical company, you need only list the pharmaceutical company.

\section{Intellectual Property.}

This section asks about patents and copyrights, whether pending, issued, licensed and/or receiving royalties.

\section{Relationships not covered above.}

Use this section to report other relationships or activities that readers could perceive to have influenced, or that give the appearance of potentially influencing, what you wrote in the submitted work.

\section{Definitions.}

Entity: government agency, foundation, commercial sponsor, academic institution, etc.

Grant: A grant from an entity, generally [but not always] paid to your organization

Personal Fees: Monies paid to you for services rendered, generally honoraria, royalties, or fees for consulting, lectures, speakers bureaus, expert testimony, employment, or other affiliations

Non-Financial Support: Examples include drugs/equipment supplied by the entity, travel paid by the entity, writing assistance, administrative support, etc.
Other: Anything not covered under the previous three boxes Pending: The patent has been filed but not issued Issued: The patent has been issued by the agency Licensed: The patent has been licensed to an entity, whether earning royalties or not

Royalties: Funds are coming in to you or your institution due to your patent 


\section{ICMJE Form for Disclosure of Potential Conflicts of Interest}

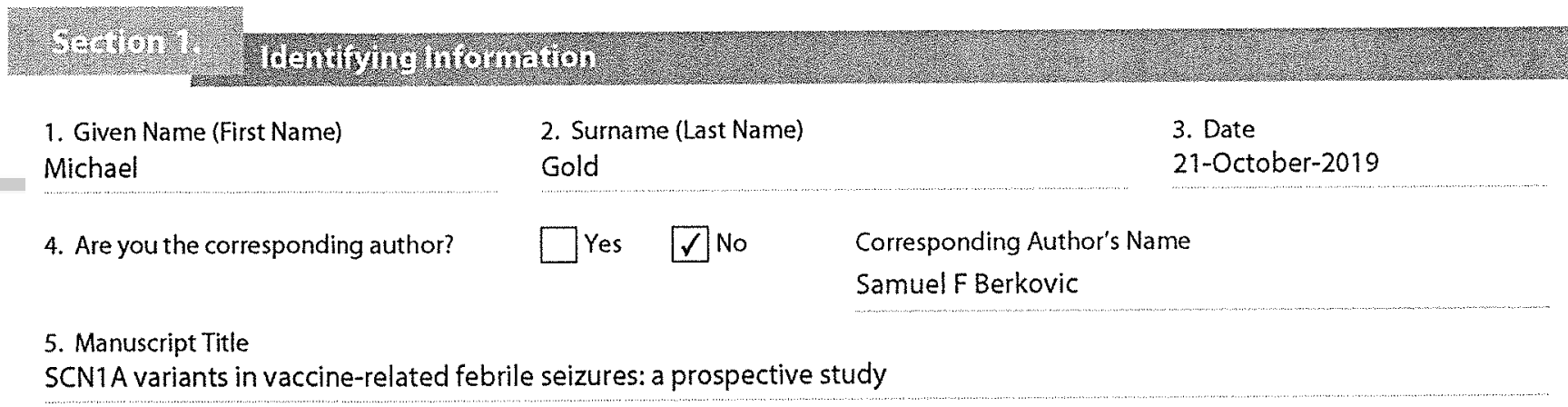

6. Manuscript Identifying Number (if you know it)

ANA-19-1109

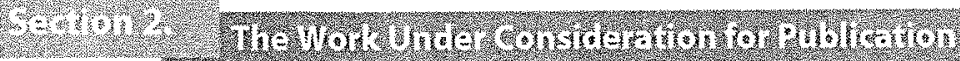

Did you or your institution at any time receive payment or services from a third party (government, commercial, private foundation, etc.) for any aspect of the submitted work (including but not limited to grants, data monitoring board, study design, manuscript preparation, statistical analysis, etc.)?

Are there any relevant conflicts of interest? $\square$ Yes $\square$ No

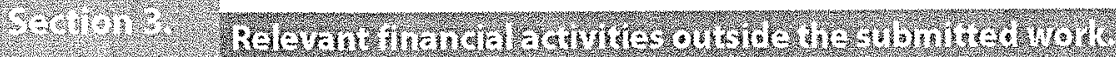

Place a check in the appropriate boxes in the table to indicate whether you have financial relationships (regardless of amount of compensation) with entities as described in the instructions. Use one line for each entity; add as many lines as you need by clicking the "Add + "box. You should report relationships that were present during the 36 months prior to publication.

Are there any relevant conflicts of interest? $\square$ Yes $\square$ No

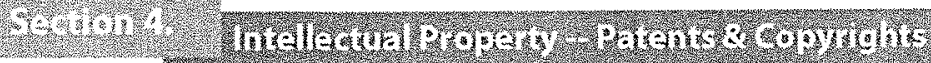

Do you have any patents, whether planned, pending or issued, broadly relevant to the work?

$\square$ Yes $\square$ No




\section{ICMJE Form for Disclosure of Potential Conflicts of Interest}

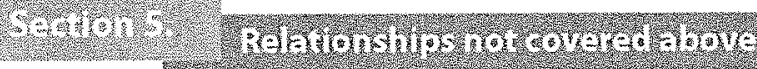

Are there other relationships or activities that readers could perceive to have influenced, or that give the appearance of potentially influencing, what you wrote in the submitted work?

$\square$ Yes, the following relationships/conditions/circumstances are present (explain below):

$\square$ No other relationships/conditions/circumstances that present a potential conflict of interest

At the time of manuscript acceptance, journals will ask authors to confirm and, if necessary, update their disclosure statements. On occasion, journals may ask authors to disclose further information about reported relationships.

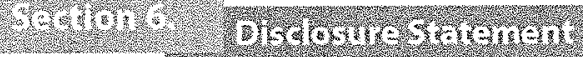

Based on the above disclosures, this form will automatically generate a disclosure statement, which will appear in the box below.

Dr. Gold has nothing to disclose.

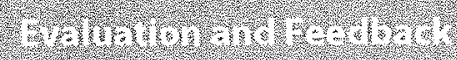

Please visit http:/www.icmie.org/cal-bin/feedback to provide feedback on your experience with completing this form. 


\section{Please wait...}

If this message is not eventually replaced by the proper contents of the document, your PDF viewer may not be able to display this type of document.

You can upgrade to the latest version of Adobe Reader for Windows®, Mac, or Linux® by visiting http://www.adobe.com/go/reader_download.

For more assistance with Adobe Reader visit http://www.adobe.com/go/acrreader.

Windows is either a registered trademark or a trademark of Microsoft Corporation in the United States and/or other countries. Mac is a trademark
of Apple Inc., registered in the United States and other countries. Linux is the registered trademark of Linus Torvalds in the U.S. and other countries. 


\section{ICMJE Form for Disclosure of Potential Conflicts of Interest}

\section{Section 1. Identifying Information}

1. Given Name (First Name) Jim

4. Are you the corresponding author?

\section{Surname (Last Name)}

Buttery
3. Date $2 1 / 1 0 \longdiv { 2 0 1 9 }$

Corresponding Author's Name

Samuel F Berkovic

5. Manuscript Title

SCN1A variants in vaccine-related febrile seizures: a prospective study

6. Manuscript Identifying Number (if you know it)

ANA-19-1109

\section{Section 2. The Work Under Consideration for Publication}

Did you or your institution at any time receive payment or services from a third party (government, commercial, private foundation, etc.) for any aspect of the submitted work (including but not limited to grants, data monitoring board, study design, manuscript preparation, statistical analysis, etc.)?

Are there any relevant conflicts of interest? $\square$ Yes $\square$ No

\section{Section 3. Relevant financial activities outside the submitted work.}

Place a check in the appropriate boxes in the table to indicate whether you have financial relationships (regardless of amount of compensation) with entities as described in the instructions. Use one line for each entity; add as many lines as you need by clicking the "Add +" box. You should report relationships that were present during the $\mathbf{3 6}$ months prior to publication. Are there any relevant conflicts of interest? $\square$ Yes $\square$ No

\section{Section 4. Intellectual Property -- Patents \& Copyrights}

Do you have any patents, whether planned, pending or issued, broadly relevant to the work? $\square$ Yes $\checkmark$ No 


\section{ICMJE Form for Disclosure of Potential Conflicts of Interest}

\section{Section 5. Relationships not covered above}

Are there other relationships or activities that readers could perceive to have influenced, or that give the appearance of potentially influencing, what you wrote in the submitted work?

Yes, the following relationships/conditions/circumstances are present (explain below):

$\checkmark$ No other relationships/conditions/circumstances that present a potential conflict of interest

At the time of manuscript acceptance, journals will ask authors to confirm and, if necessary, update their disclosure statements On occasion, journals may ask authors to disclose further information about reported relationships.

\section{Section 6.}

\section{Disclosure Statement}

Based on the above disclosures, this form will automatically generate a disclosure statement, which will appear in the box helow.

\section{Evaluation and Feedback}

Please visit http://www.icmje.org/cgi-bin/feedback to provide feedback on your experience with completing this form. 


\section{Instructions}

The purpose of this form is to provide readers of your manuscript with information about your other interests that could influence how they receive and understand your work. The form is designed to be completed electronically and stored electronically. It contains programming that allows appropriate data display. Each author should submit a separate form and is responsible for the accuracy and completeness of the submitted information. The form is in six parts.

\section{Identifying information.}

\section{The work under consideration for publication.}

This section asks for information about the work that you have submitted for publication. The time frame for this reporting is that of the work itself, from the initial conception and planning to the present. The requested information is about resources that you received, either directly or indirectly (via your institution), to enable you to complete the work. Checking "No" means that you did the work without receiving any financial support from any third party -- that is, the work was supported by funds from the same institution that pays your salary and that institution did not receive third-party funds with which to pay you. If you or your institution received funds from a third party to support the work, such as a government granting agency, charitable foundation or commercial sponsor, check "Yes".

\section{Relevant financial activities outside the submitted work.}

This section asks about your financial relationships with entities in the bio-medical arena that could be perceived to influence, or that give the appearance of potentially influencing, what you wrote in the submitted work. You should disclose interactions with ANY entity that could be considered broadly relevant to the work. For example, if your article is about testing an epidermal growth factor receptor (EGFR) antagonist in lung cancer, you should report all associations with entities pursuing diagnostic or therapeutic strategies in cancer in general, not just in the area of EGFR or lung cancer.

Report all sources of revenue paid (or promised to be paid) directly to you or your institution on your behalf over the 36 months prior to submission of the work. This should include all monies from sources with relevance to the submitted work, not just monies from the entity that sponsored the research. Please note that your interactions with the work's sponsor that are outside the submitted work should also be listed here. If there is any question, it is usually better to disclose a relationship than not to do so.

For grants you have received for work outside the submitted work, you should disclose support ONLY from entities that could be perceived to be affected financially by the published work, such as drug companies, or foundations supported by entities that could be perceived to have a financial stake in the outcome. Public funding sources, such as government agencies, charitable foundations or academic institutions, need not be disclosed. For example, if a government agency sponsored a study in which you have been involved and drugs were provided by a pharmaceutical company, you need only list the pharmaceutical company.

\section{Intellectual Property.}

This section asks about patents and copyrights, whether pending, issued, licensed and/or receiving royalties.

\section{Relationships not covered above.}

Use this section to report other relationships or activities that readers could perceive to have influenced, or that give the appearance of potentially influencing, what you wrote in the submitted work.

\section{Definitions.}

Entity: government agency, foundation, commercial sponsor, academic institution, etc.

Grant: A grant from an entity, generally [but not always] paid to your organization

Personal Fees: Monies paid to you for services rendered, generally honoraria, royalties, or fees for consulting, lectures, speakers bureaus, expert testimony, employment, or other affiliations

Non-Financial Support: Examples include drugs/equipment supplied by the entity, travel paid by the entity, writing assistance, administrative support, etc.
Other: Anything not covered under the previous three boxes Pending: The patent has been filed but not issued Issued: The patent has been issued by the agency Licensed: The patent has been licensed to an entity, whether earning royalties or not

Royalties: Funds are coming in to you or your institution due to your patent 


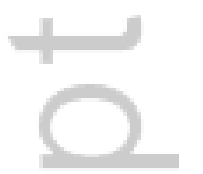




\section{ICMJE Form for Disclosure of Potential Conflicts of Interest}

\section{Sestion 1. Identifing Information}
1. Given Name (First Name)
2. Surname (Last Name)
Macartney Kristine

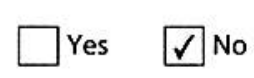
Corresponding Author's Name
Samuel F Berkovic
4. Are you the corresponding author?
3. Date
15-October-2019

5. Manuscript Title

SCN1A variants in vaccine-related febrile seizures: a prospective study

6. Manuscript Identifying Number (if you know it)

ANA-19-1109

\section{Section 2. The Work Under consideration for Publication}

Did you or your institution at any time receive payment or services from a third party (government, commercial, private foundation, etc.) for any aspect of the submitted work (including but not limited to grants, data monitoring board, study design, manuscript preparation, statistical analysis, etc.)?

Are there any relevant conflicts of interest? $\square$ Yes $\square$ No

\section{Section 3. Relevant financial activities outside the submitted work.}

Place a check in the appropriate boxes in the table to indicate whether you have financial relationships (regardless of amount of compensation) with entities as described in the instructions. Use one line for each entity; add as many lines as you need by clicking the "Add +" box. You should report relationships that were present during the $\mathbf{3 6}$ months prior to publication.

Are there any relevant conflicts of interest? $\square$ Yes $\square$ No

\section{Section 4. Intellectual Property-Patents \& Copyrights}

Do you have any patents, whether planned, pending or issued, broadly relevant to the work? $\square$ Yes $\square$ No 


\section{ICMJE Form for Disclosure of Potential Conflicts of Interest}

\section{Stction 5. Relationships not covered above}

Are there other relationships or activities that readers could perceive to have influenced, or that give the appearance of potentially influencing, what you wrote in the submitted work?

Yes, the following relationships/conditions/circumstances are present (explain below):

$\checkmark$ No other relationships/conditions/circumstances that present a potential conflict of interest

At the time of manuscript acceptance, journals will ask authors to confirm and, if necessary, update their disclosure statements. On occasion, journals may ask authors to disclose further information about reported relationships.

\section{Segtion 6. Disclosure Statement}

Based on the above disclosures, this form will automatically generate a disclosure statement, which will appear in the box below.

Dr. Macartney has nothing to disclose.

\section{Braluation and Feedback}

Please visit http://www.icmje.org/cgi-bin/feedback to provide feedback on your experience with completing this form. 


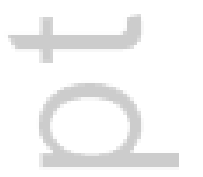




\section{ICMJE Form for Disclosure of Potential Conflicts of Interest}

\section{Instructions}

The purpose of this form is to provide readers of your manuscript with information about your other interests that could influence how they receive and understand your work. The form is designed to be completed electronically and stored electronically. It contains programming that allows appropriate data display. Each author should submit a separate form and is responsible for the accuracy and completeness of the submitted information. The form is in six parts.

\section{Identifying information.}

\section{The work under consideration for publication.}

This section asks for information about the work that you have submitted for publication. The time frame for this reporting is that of the work itself, from the initial conception and planning to the present. The requested information is about resources that you received, either directly or indirectly (via your institution), to enable you to complete the work. Checking "No" means that you did the work without receiving any financial support from any third party -- that is, the work was supported by funds from the same institution that pays your salary and that institution did not receive third-party funds with which to pay you. If you or your institution received funds from a third party to support the work, such as a government granting agency, charitable foundation or commercial sponsor, check "Yes".

\section{Relevant financial activities outside the submitted work.}

This section asks about your financial relationships with entities in the bio-medical arena that could be perceived to influence, or that give the appearance of potentially influencing, what you wrote in the submitted work. You should disclose interactions with ANY entity that could be considered broadly relevant to the work. For example, if your article is about testing an epidermal growth factor receptor (EGFR) antagonist in lung cancer, you should report all associations with entities pursuing diagnostic or therapeutic strategies in cancer in general, not just in the area of EGFR or lung cancer.

Report all sources of revenue paid (or promised to be paid) directly to you or your institution on your behalf over the 36 months prior to submission of the work. This should include all monies from sources with relevance to the submitted work, not just monies from the entity that sponsored the research. Please note that your interactions with the work's sponsor that are outside the submitted work should also be listed here. If there is any question, it is usually better to disclose a relationship than not to do so.

For grants you have received for work outside the submitted work, you should disclose support ONLY from entities that could be perceived to be affected financially by the published work, such as drug companies, or foundations supported by entities that could be perceived to have a financial stake in the outcome. Public funding sources, such as government agencies, charitable foundations or academic institutions, need not be disclosed. For example, if a government agency sponsored a study in which you have been involved and drugs were provided by a pharmaceutical company, you need only list the pharmaceutical company.

\section{Intellectual Property.}

This section asks about patents and copyrights, whether pending, issued, licensed and/or receiving royalties.

\section{Relationships not covered above.}

Use this section to report other relationships or activities that readers could perceive to have influenced, or that give the appearance of potentially influencing, what you wrote in the submitted work.

\section{Definitions.}

Entity: government agency, foundation, commercial sponsor, academic institution, etc.

Grant: A grant from an entity, generally [but not always] paid to your organization

Personal Fees: Monies paid to you for services rendered, generally honoraria, royalties, or fees for consulting , lectures, speakers bureaus, expert testimony, employment, or other affiliations

Non-Financial Support: Examples include drugs/equipment supplied by the entity, travel paid by the entity, writing assistance, administrative support, etc.
Other: Anything not covered under the previous three boxes Pending: The patent has been filed but not issued Issued: The patent has been issued by the agency Licensed: The patent has been licensed to an entity, whether earning royalties or not Royalties: Funds are coming in to you or your institution due to your patent 


\section{ICMJE Form for Disclosure of Potential Conflicts of Interest}

\section{Section 1. Identifying Information}

1. Given Name (First Name)

Peter

4. Are you the corresponding author?
2. Surname (Last Name)

Richmond

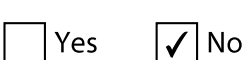

3. Date

15-October-2019

Corresponding Author's Name

Samuel F Berkovic

5. Manuscript Title

SCN1A variants in vaccine-related febrile seizures: a prospective study

6. Manuscript Identifying Number (if you know it)

ANA-19-1109

\section{Section 2. The Work Under Consideration for Publication}

Did you or your institution at any time receive payment or services from a third party (government, commercial, private foundation, etc.) for any aspect of the submitted work (including but not limited to grants, data monitoring board, study design, manuscript preparation, statistical analysis, etc.)?

Are there any relevant conflicts of interest? $\square$ Yes $\square$ No

\section{Section 3. Relevant financial activities outside the submitted work.}

Place a check in the appropriate boxes in the table to indicate whether you have financial relationships (regardless of amount of compensation) with entities as described in the instructions. Use one line for each entity; add as many lines as you need by clicking the "Add +" box. You should report relationships that were present during the $\mathbf{3 6}$ months prior to publication.

Are there any relevant conflicts of interest? $\square$ Yes $\square$ No

\section{Section 4. Intellectual Property -- Patents \& Copyrights}

Do you have any patents, whether planned, pending or issued, broadly relevant to the work? $\square$ Yes $\square$ No 


\section{ICMJE Form for Disclosure of Potential Conflicts of Interest}

\section{Section 5. Relationships not covered above}

Are there other relationships or activities that readers could perceive to have influenced, or that give the appearance of potentially influencing, what you wrote in the submitted work?

$\square$ Yes, the following relationships/conditions/circumstances are present (explain below):

$\checkmark$ No other relationships/conditions/circumstances that present a potential conflict of interest

At the time of manuscript acceptance, journals will ask authors to confirm and, if necessary, update their disclosure statements. On occasion, journals may ask authors to disclose further information about reported relationships.

\section{Section 6.}

\section{Disclosure Statement}

Based on the above disclosures, this form will automatically generate a disclosure statement, which will appear in the box below.

Dr. Richmond has nothing to disclose.

\section{Evaluation and Feedback}

Please visit http://www.icmje.org/cgi-bin/feedback to provide feedback on your experience with completing this form. 


\section{Please wait...}

If this message is not eventually replaced by the proper contents of the document, your PDF viewer may not be able to display this type of document.

You can upgrade to the latest version of Adobe Reader for Windows®, Mac, or Linux® by visiting http://www.adobe.com/go/reader_download.

For more assistance with Adobe Reader visit http://www.adobe.com/go/acrreader.

Windows is either a registered trademark or a trademark of Microsoft Corporation in the United States and/or other countries. Mac is a trademark
of Apple Inc., registered in the United States and other countries. Linux is the registered trademark of Linus Torvalds in the U.S. and other countries. 


\section{Please wait...}

If this message is not eventually replaced by the proper contents of the document, your PDF viewer may not be able to display this type of document.

You can upgrade to the latest version of Adobe Reader for Windows®, Mac, or Linux® by visiting http://www.adobe.com/go/reader_download.

For more assistance with Adobe Reader visit http://www.adobe.com/go/acrreader.

Windows is either a registered trademark or a trademark of Microsoft Corporation in the United States and/or other countries. Mac is a trademark
of Apple Inc., registered in the United States and other countries. Linux is the registered trademark of Linus Torvalds in the U.S. and other countries. 
Table 1: Clinical details for Vaccine Proximate-FS (VP-FS), Non-Vaccine Proximate-FS (NVPFS) and control groups

\begin{tabular}{lllll}
\hline & $\begin{array}{l}\text { VP-FS } \\
\mathbf{n}(\%)\end{array}$ & $\begin{array}{l}\text { NVP-FS } \\
\mathbf{n}(\%)\end{array}$ & $\begin{array}{l}\text { Control } \\
\mathbf{n}(\%)\end{array}$ & $\mathbf{p}^{*}$ \\
\hline $\mathrm{n}$ & 69 & 75 & 90 & \\
$\begin{array}{l}\text { Sex (male) } \\
\text { Family history FS }\end{array}$ & $37(53.6 \%)$ & $32(42.7 \%)$ & $55(61.1 \%)$ & 0.06 \\
$\quad$ FS & $25(36.2 \%)$ & $25(33.3 \%)$ & NA & 0.72 \\
$\quad$ Epilepsy & $9(13.0 \%)$ & $13(17.3 \%)$ & NA & 0.47 \\
First FS & & & & \\
$\quad$ Age (months) & $12.8($ SD 3.8) & $14.3($ SD 5.2) & NA & 0.05 \\
$\quad$ Complex FS & $27(39.1 \%)$ & $17(22.7 \%)$ & NA & 0.03 \\
FS recurrence & & & & \\
$\quad$ Follow up duration (months) & $16.1(\mathrm{SD} \mathrm{4.8)}$ & $17.2(\mathrm{SD} 3.2)$ & NA & 0.09 \\
$\quad$ FS recurrence & $26(37.7 \%)$ & $26(34.7 \%)$ & NA & 0.71 \\
$\quad$ AFS following initial FS & $8(11.6 \%)$ & $4(5.3 \%)$ & NA & 0.23 \\
\hline
\end{tabular}

$\mathrm{FS}=$ febrile seizure, $\mathrm{AFS}=$ afebrile seizure, $\mathrm{SD}=$ standard deviation, NA=not applicable

Complex FS = febrile seizure $>15$ minutes, focal seizure or repeat seizure within $24 \mathrm{~h}$ of initial *Where there is no value for control group, $p$ value compares VP-FS and NVP-FS groups only 
Table 2: SCN1A variants by group allocation and variant class

\begin{tabular}{lccc}
\hline ACMG Variant Class(23) & $\begin{array}{c}\text { VP-FS } \\
(\mathrm{n}=69)\end{array}$ & $\begin{array}{c}\text { NVP-FS } \\
(\mathrm{n}=75)\end{array}$ & $\begin{array}{c}\text { Control } \\
(\mathrm{n}=90)\end{array}$ \\
\hline Pathogenic & 1 & 0 & 0 \\
Likely pathogenic & 1 & 1 & 0 \\
Unknown significance* & 4 & 8 & 4 \\
Likely benign $_{\text {Benign }}^{*}$ & 2 & 2 & 4 \\
\hline
\end{tabular}

VP-FS=vaccine proximate febrile seizure, NVP-FS=non-vaccine proximate febrile seizure ACMG = American College of Medical Genetics

* Variants of unknown significance were all intronic in VP-FS and control groups; NVP-FS group had three missense, 1 synonymous and four intronic variants 
Table 3: Clinical characteristics of participants with pathogenic/likely pathogenic variants

\begin{tabular}{|c|c|c|c|c|c|c|c|c|}
\hline \multirow{2}{*}{$\begin{array}{l}\text { Case } \\
\text { (sex) }\end{array}$} & \multirow[t]{2}{*}{ Group } & \multicolumn{3}{|c|}{ First FS } & \multirow{2}{*}{$\begin{array}{l}\text { Vaccine } \\
\text { (seizure } \\
\text { onset time } \\
\text { post- } \\
\text { vaccination) }\end{array}$} & \multirow{2}{*}{$\begin{array}{l}\text { Later } \\
\text { seizures }\end{array}$} & \multirow{2}{*}{$\begin{array}{l}\text { Epilepsy } \\
\text { syndrome }\end{array}$} & \multirow{2}{*}{$\begin{array}{l}\text { SCN1A } \\
\text { variant }^{\dagger}\end{array}$} \\
\hline & & $\begin{array}{l}\text { Age } \\
\text { (months) }\end{array}$ & $\begin{array}{l}\text { Duration } \\
\text { (minutes) }\end{array}$ & Description & & & & \\
\hline $1 \mathrm{M}$ & VP-FS & 4.0 & 30 & GTCS & $\begin{array}{l}\text { DTPa-IPV- } \\
\text { HepB-HiB, } \\
\text { PCV13, } \\
\text { rotavirus } \\
\text { (10 hours) }\end{array}$ & $\mathrm{M}, \mathrm{Ab}, \mathrm{GTCS}$ & Dravet & $\begin{array}{l}\text { c.1702C>T; } \\
\text { p.R568X } \\
\text { Pathogenic\# }\end{array}$ \\
\hline $2 \mathrm{M}$ & VP-FS & 4.4 & 15 & GTCS & $\begin{array}{l}\text { DTPa-IPV- } \\
\text { HepB-HiB, } \\
\text { PCV13, } \\
\text { rotavirus } \\
\text { (18 hours) }\end{array}$ & $\begin{array}{l}\text { M, GCS, } \\
\text { GTCS, H, SE }\end{array}$ & Dravet & $\begin{array}{l}\text { c. } 2794 \mathrm{~T}>\mathrm{A} \text {; } \\
\text { p.W932R } \\
\text { Likely } \\
\text { Pathogenic* }\end{array}$ \\
\hline $3 \mathrm{M}$ & $\begin{array}{l}\text { NVP- } \\
\text { FS }\end{array}$ & 9.7 & 57 & GTCS & NA & GTCS & FS+ & $\begin{array}{l}\text { c.2839 G>T; } \\
\text { p.V947L } \\
\text { Likely } \\
\text { Pathogenic^ }^{n}\end{array}$ \\
\hline
\end{tabular}

FS=febrile seizure, VP-FS=vaccine proximate FS, NVP-FS=non-vaccine proximate FS, FS $+=$ febrile seizures plus

DTPa-IPV-HepB-HiB=hexavalent diphtheria, tetanus, acellular pertussis, inactivated polio, hepatitis B, haemophilus influenza $B$ vaccine

PCV13=13 valent pneumococcal conjugate vaccine

GTCS=generalised tonic-clonic seizures; GCS=generalised clonic seizures; $M=$ =myoclonic seizures;

$\mathrm{Ab}=$ =absences; $\mathrm{SE}=$ status epilepticus; $\mathrm{H}=$ hemiclonic; $\mathrm{NA}=$ not applicable.

${ }^{\dagger}$ Classification according to ACMG guidelines (23) is listed and qualifying criteria specified

\# Null variant, previously reported $(8,29)$

* Novel missense change at an amino acid residue where a different missense change determined to be pathogenic has been seen before (39); located in a mutational hot spot; absent from controls

$\wedge$ Located in a mutational hot spot; absent from controls; Multiple lines of computational evidence support a deleterious effect on the gene, Missense variant in a gene that has a low rate of benign missense variation and in which missense variants are a common mechanism of disease 
Table 4: Allele frequency differences for the 5 common single nucleotide polymorphisms (SNPs) detected within SCN1A

\begin{tabular}{|c|c|c|c|c|c|}
\hline \multirow[b]{2}{*}{ Variant } & \multirow[b]{2}{*}{ Location } & \multirow[b]{2}{*}{ Rs number } & \multicolumn{3}{|c|}{ Minor Allele Frequency (MAF) } \\
\hline & & & Febrile Seizures $^{a}$ & Controls & $\mathrm{p}^{*}$ \\
\hline $\begin{array}{l}\text { c. } 2292 ; \mathrm{C}>\mathrm{T} ; \\
\text { p.V764V }\end{array}$ & Exon 13 & rs6432860 & $148 / 288(0.51)$ & $64 / 180(0.36)$ & 0.004 \\
\hline $\begin{array}{l}\text { c. } 1212 \text { A>G; } \\
\text { p.V404V }\end{array}$ & Exon 9 & rs7580482 & $137 / 288(0.48)$ & $67 / 180(0.37)$ & 0.14 \\
\hline $\begin{array}{l}\text { c.3199 G>A; } \\
\text { p. A1067T }\end{array}$ & Exon 16 & rs2298771 & $75 / 288(0.26)$ & $54 / 180(0.30)$ & 1.00 \\
\hline c. $603-91 \mathrm{G}>\mathrm{A}$ & Intron 4 & rs3812718 & $117 / 288(0.41)$ & $81 / 180(0.45)$ & 1.00 \\
\hline c.603-106 T>G & Intron 4 & rs3812719 & 55/288 (0.19) & $53 / 180(0.29)$ & 0.50 \\
\hline
\end{tabular}

a Includes both VP-FS and NVP-FS cases

${ }^{*} \mathrm{p}$ value corrected for multiple comparisons using Bonferroni method using 5 tests

This article is protected by copyright. All rights reserved. 
Table 5: Allele frequency comparisons for single nucleotide polymorphism (SNP) c.2292; C>T; p.V764V; rs6432860 according to clinical groups assignment

\begin{tabular}{|c|c|c|c|c|}
\hline \multirow[b]{2}{*}{ Analyses } & \multicolumn{4}{|c|}{ Minor Allele Frequency (MAF) } \\
\hline & Cases (\%) & Controls & OR (95\% Cl) & $p^{*}$ \\
\hline VP-FS vs. controls & $74 / 138(53.6 \%)$ & $64 / 180(35.5 \%)$ & $2.10(1.33-3.30)$ & 0.17 \\
\hline NVP-FS vs. controls & $74 / 150(49.3 \%)$ & $64 / 180(35.5 \%)$ & $1.77(1.13-2.75)$ & 0.40 \\
\hline VP-FS vs. NVP-FS & 74/138 (53.6\%) & $74 / 150(49.3 \%)$ & $1.19(0.75-1.89)$ & 1.00 \\
\hline All FS vs. controls & $148 / 288(51.4 \%)$ & $64 / 180(35.6 \%)$ & 1.91 (1.31- 2.81) & 0.003 \\
\hline
\end{tabular}

FS=febrile seizure, VP-FS=vaccine proximate FS, NVP-FS=non-vaccine proximate FS

${ }^{*} p$ value corrected for multiple comparisons using Bonferroni method using 4 tests

This article is protected by copyright. All rights reserved. 


\section{ICMJE Form for Disclosure of Potential Conflicts of Interest}

\section{Instruatons}

The purpose of this form is to provide readers of your manuscript with information about your other interests that could influence how they receive and understand your work. The form is designed to be completed electronically and stored electronically. It contains programming that allows appropriate data display. Each author should submit a separate form and is responsible for the accuracy and completeness of the submitted information. The form is in six parts.

\section{Identifying information.}

\section{The work under consideration for publication.}

This section asks for information about the work that you have submitted for publication. The time frame for this reporting is that of the work itself, from the initial conception and planning to the present. The requested information is about resources that you received, either directly or indirectly (via your institution), to enable you to complete the work. Checking "No" means that you did the work without receiving any financial support from any third party -- that is, the work was supported by funds from the same institution that pays your salary and that institution did not receive third-party funds with which to pay you. If you or your institution received funds from a third party to support the work, such as a government granting agency, charitable foundation or commercial sponsor, check "Yes".

\section{Relevant financial activities outside the submitted work.}

This section asks about your financial relationships with entities in the bio-medical arena that could be perceived to influence, or that give the appearance of potentially influencing, what you wrote in the submitted work. You should disclose interactions with ANY entity that could be considered broadly relevant to the work. For example, if your article is about testing an epidermal growth factor receptor (EGFR) antagonist in lung cancer, you should report all associations with entities pursuing diagnostic or therapeutic strategies in cancer in general, not just in the area of EGFR or lung cancer.

Report all sources of revenue paid (or promised to be paid) directly to you or your institution on your behalf over the 36 months prior to submission of the work. This should include all monies from sources with relevance to the submitted work, not just monies from the entity that sponsored the research. Please note that your interactions with the work's sponsor that are outside the submitted work should also be listed here. If there is any question, it is usually better to disclose a relationship than not to do so.

For grants you have received for work outside the submitted work, you should disclose support ONLY from entities that could be perceived to be affected financially by the published work, such as drug companies, or foundations supported by entities that could be perceived to have a financial stake in the outcome. Public funding sources, such as government agencies, charitable foundations or academic institutions, need not be disclosed. For example, if a government agency sponsored a study in which you have been involved and drugs were provided by a pharmaceutical company, you need only list the pharmaceutical company.

\section{Intellectual Property.}

This section asks about patents and copyrights, whether pending, issued, licensed and/or receiving royalties.

\section{Relationships not covered above.}

Use this section to report other relationships or activities that readers could perceive to have influenced, or that give the appearance of potentially influencing, what you wrote in the submitted work.

\section{Definitions.}

Entity: government agency, foundation, commercial sponsor, academic institution, etc.

Grant: A grant from an entity, generally [but not always] paid to your organization

Personal Fees: Monies paid to you for services rendered, generally honoraria, royalties, or fees for consulting, lectures, speakers bureaus, expert testimony, employment, or other affiliations

Non-Financial Support: Examples include drugs/equipment supplied by the entity, travel paid by the entity, writing assistance, administrative support, etc.
Other: Anything not covered under the previous three boxes Pending: The patent has been filed but not issued Issued: The patent has been issued by the agency Licensed: The patent has been licensed to an entity, whether earning royalties or not

Royalties: Funds are coming in to you or your institution due to you patent 


\section{ICMJE Form for Disclosure of Potential Conflicts of Interest}

\section{Section 1 Tentifying Information}

1. Given Name (First Name)

Wenhui

4. Are you the corresponding author?

5. Manuscript Title

SCN1A variants in vaccine-related febrile seizures: a prospective study

6. Manuscript Identifying Number (if you know it)

ANA-19-1109

\section{Seation 2. The Work Under consteration for Publisation}

Did you or your institution at any time receive payment or services from a third party (government, commercial, private foundation, etc.) for any aspect of the submitted work (including but not limited to grants, data monitoring board, study design, manuscript preparation, statistical analysis, etc.)?

Are there any relevant conflicts of interest? $\square$ Yes $\square$ No

\section{Section 3. Relevant financial activities outside the submitred work.}

Place a check in the appropriate boxes in the table to indicate whether you have financial relationships (regardless of amount of compensation) with entities as described in the instructions. Use one line for each entity; add as many lines as you need by clicking the "Add +" box. You should report relationships that were present during the $\mathbf{3 6}$ months prior to publication.

Are there any relevant conflicts of interest? $\square$ Yes $\square$ No

\section{Section 4. Intellectual propenty - patents \& Copynights}

Do you have any patents, whether planned, pending or issued, broadly relevant to the work? $\square$ Yes $\square$ No 


\section{ICMJE Form for Disclosure of Potential Conflicts of Interest}

\section{Section 5. Relationships not covered above}

Are there other relationships or activities that readers could perceive to have influenced, or that give the appearance of potentially influencing, what you wrote in the submitted work?

$\square$ Yes, the following relationships/conditions/circumstances are present (explain below):

$\checkmark$ No other relationships/conditions/circumstances that present a potential conflict of interest

At the time of manuscript acceptance, journals will ask authors to confirm and, if necessary, update their disclosure statements. On occasion, journals may ask authors to disclose further information about reported relationships.

\section{Secton 6.}

\section{Disclosure Statement}

Based on the above disclosures, this form will automatically generate a disclosure statement, which will appear in the box below.

Dr. Li has nothing to disclose.

\section{Evaluation and Fered back}

Please visit http://www.icmje.org/cgi-bin/feedback to provide feedback on your experience with completing this form. 


\section{ICMJE Form for Disclosure of Potential Conflicts of Interest}

\section{Instructions}

The purpose of this form is to provide readers of your manuscript with information about your other interests that could influence how they receive and understand your work. The form is designed to be completed electronically and stored electronically. It contains programming that allows appropriate data display. Each author should submit a separate form and is responsible for the accuracy and completeness of the submitted information. The form is in six parts.

\section{Identifying information.}

\section{The work under consideration for publication.}

This section asks for information about the work that you have submitted for publication. The time frame for this reporting is that of the work itself, from the initial conception and planning to the present. The requested information is about resources that you received, either directly or indirectly (via your institution), to enable you to complete the work. Checking "No" means that you did the work without receiving any financial support from any third party - that is, the work was supported by funds from the same institution that pays your salary and that institution did not receive third-party funds with which to pay you. If you or your institution received funds from a third party to support the work, such as a government granting agency, charitable foundation or commercial sponsor, check "Yes".

\section{Relevant financial activities outside the submitted work.}

This section asks about your financial relationships with entities in the bio-medical arena that could be perceived to influence, or that give the appearance of potentially influencing, what you wrote in the submitted work. You should disclose interactions with ANY entity that could be considered broadly relevant to the work. For example, if your article is about testing an epidermal growth factor receptor (EGFR) antagonist in lung cancer, you should report all associations with entities pursuing diagnostic or therapeutic strategies in cancer in general, not just in the area of EGFR or lung cancer.

Report all sources of revenue paid (or promised to be paid) directly to you or your institution on your behalf over the 36 months prior to submission of the work. This should include all monies from sources with relevance to the submitted work, not just monies from the entity that sponsored the research. Please note that your interactions with the work's sponsor that are outside the submitted work should also be listed here. If there is any question, it is usually better to disclose a relationship than not to do so.

For grants you have received for work outside the submitted work, you should disclose support ONLY from entities that could be perceived to be affected financially by the published work, such as drug companies, or foundations supported by entities that could be perceived to have a financial stake in the outcome. Public funding sources, such as government agencies, charitable foundations or academic institutions, need not be disclosed. For example, if a government agency sponsored a study in which you have been involved and drugs were provided by a pharmaceutical company, you need only list the pharmaceutical company.

\section{Intellectual Property.}

This section asks about patents and copyrights, whether pending, issued, licensed and/or receiving royalties.

\section{Relationships not covered above.}

Use this section to report other relationships or activities that readers could perceive to have influenced, or that give the appearance of potentially influencing, what you wrote in the submitted work.

\section{Definitions.}

Entity: government agency, foundation, commercial sponsor, academic institution, etc.

Grant: A grant from an entity, generally [but not always] paid to your organization

Personal Fees: Monies paid to you for services rendered, generally honoraria, royalties, or fees for consulting , lectures, speakers bureaus, expert testimony, employment, or other affiliations

Non-Financial Support: Examples include drugs/equipment supplied by the entity, travel paid by the entity, writing assistance, administrative support, etc.
Other: Anything not covered under the previous three boxes Pending: The patent has been filed but not issued Issued: The patent has been issued by the agency Licensed: The patent has been licensed to an entity, whether earning royalties or not

Royalties: Funds are coming in to you or your institution due to your patent 


\section{ICMJE Form for Disclosure of Potential Conflicts of Interest}

\section{Section 1. \\ Identifying Information}

1. Given Name (First Name)

Nicholas

4. Are you the corresponding author?

5. Manuscript Title

SCN1A variants in vaccine-related febrile seizures: a prospective study

6. Manuscript Identifying Number (if you know it)

ANA-19-1109

\section{Section 2.}

\section{The Work Under Consideration for Publication}

Did you or your institution at any time receive payment or services from a third party (government, commercial, private foundation, etc.) for any aspect of the submitted work (including but not limited to grants, data monitoring board, study design, manuscript preparation, statistical analysis, etc.)?

Are there any relevant conflicts of interest? $\square$ Yes $\square$ No

If yes, please fill out the appropriate information below. If you have more than one entity press the "ADD" button to add a row. Excess rows can be removed by pressing the " $\mathrm{X}$ " button.

\section{Name of Institution/Company}

\begin{tabular}{|c|c|c|}
\hline Grant? & $\begin{array}{c}\text { Personal } \\
\text { Fees? }\end{array}$ & $\begin{array}{c}\text { Non-Financial } \\
\text { Support? }\end{array}$ \\
\hline
\end{tabular}

National Health and Medical Research Council Australia $\checkmark$
Samuel F Berkovic $\square$ Yes $\square$ No $\quad$ Corresponding Author's Name

$\begin{array}{ll}\text { 2. Surname (Last Name) } & \text { 3. Date } \\ \text { Wood } & \text { 17-October-2019 }\end{array}$

$\begin{array}{ll}\text { 2. Surname (Last Name) } & \text { 3. Date } \\ \text { Wood } & \text { 17-October-2019 }\end{array}$

(1) 


\section{ICMJE Form for Disclosure of Potential Conflicts of Interest}

\section{Section 5. Relationships not coveredabove}

Are there other relationships or activities that readers could perceive to have influenced, or that give the appearance of potentially influencing, what you wrote in the submitted work?

Yes, the following relationships/conditions/circumstances are present (explain below):

No other relationships/conditions/circumstances that present a potential conflict of interest

At the time of manuscript acceptance, journals will ask authors to confirm and, if necessary, update their disclosure statements. On occasion, journals may ask authors to disclose further information about reported relationships.

\section{Section 6. Disclosure Statement}

Based on the above disclosures, this form will automatically generate a disclosure statement, which will appear in the box below.

Dr. Wood reports grants from National Health and Medical Research Council Australia, during the conduct of the study; .

\section{Evaluation and Feedback}

Please visit http://www.icmje.org/cgi-bin/feedback to provide feedback on your experience with completing this form. 


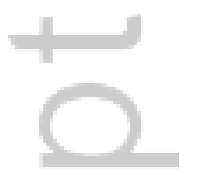




\section{University Library}

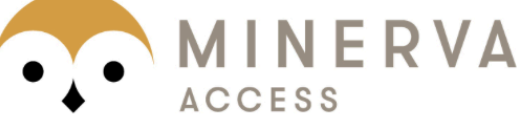

A gateway to Melbourne's research publications

Minerva Access is the Institutional Repository of The University of Melbourne

\section{Author/s:}

Damiano, JA;Deng, L;Li, W;Burgess, R;Schneider, AL;Crawford, NW;Buttery, J;Gold, M;Richmond, P;Macartney, KK;Hildebrand, MS;Scheffer, IE;Wood, N;Berkovic, SF

Title:

SCN1A Variants in vaccine-related febrile seizures: A prospective study

Date:

2019-12-12

\section{Citation:}

Damiano, J. A., Deng, L., Li, W., Burgess, R., Schneider, A. L., Crawford, N. W., Buttery, J., Gold, M., Richmond, P., Macartney, K. K., Hildebrand, M. S., Scheffer, I. E., Wood, N. \& Berkovic, S. F. (2019). SCN1A Variants in vaccine-related febrile seizures: A prospective study. ANNALS OF NEUROLOGY, 87 (2), pp.281-288. https://doi.org/10.1002/ana.25650.

Persistent Link:

http://hdl.handle.net/11343/286735 